Journal of Management

Vol. 45 No. 4, April 2019 1689-1712

DOI: $10.1177 / 0149206317733510$

(C) The Author(s) 2017

Article reuse guidelines:

sagepub.com/journals-permissions

\title{
Conveyed Leader PsyCap Predicting Leader Effectiveness Through Positive Energizing
}

\author{
Arménio Rego \\ Católica Porto Business School \\ Instituto Universitário de Lisboa \\ Kai Chi Yam \\ National University of Singapore \\ Bradley P. Owens \\ Brigham Young University \\ Joana S. P. Story \\ Miguel Pina e Cunha \\ Universidade Nova de Lisboa \\ Dustin Bluhm \\ University of Colorado Colorado Springs \\ Miguel Pereira Lopes \\ Universidade de Lisboa
}

Whereas past research on psychological capital (PsyCap) has tended to focus on how one's self-attributed PsyCap affects one's work behaviors, we extend this literature by examining the concept of conveyed PsyCap and its downstream consequences, above and beyond the influence of self-attributed PsyCap. Drawing from the emotions-as-social-information model, we tested a model of conveyed leader PsyCap predicting leader effectiveness through team

\footnotetext{
Acknowledgments: This article was accepted under the editorship of Patrick M. Wright. The authors are very grateful to the editor in action, Daniel J. Beal, and the two reviewers for their helpful comments and recommendations. The comments of Filipa Castanheira, Fred Luthans, Pedro Neves, and Susana Leal were also very helpful. This work was supported by (a) Fundação para a Ciência e Tecnologia (Grant UID/GES/00315/2013; project ref. UID/ECO/00124/2013), (b) POR Lisboa (Project LISBOA-01-0145-FEDER-007722), (c) a grant from the Templeton Foundation-Developing Humility in Leadership (60622), and (d) a fellowship from the Wheatley Institution at Brigham Young University.

Supplemental material for this article is available with the manuscript on the JOM website.

Corresponding author: Arménio Rego, Católica Porto Business School, Universidade Católica Portuguesa, Rua de Diogo Botelho, 1327, 4169-005 Porto, Portugal.
}

Email: arego@porto.ucp.pt 
positive energizing. A laboratory experiment and a multisource study provided support for our hypotheses. We furthermore found that a leader's within-team consistency in conveyed PsyCap moderates these effects, such that leaders who are more consistent in conveyed PsyCap are rated by followers as better leaders, via the mediating effect of team positive energizing. A post hoc analysis further suggests that conveyed PsyCap is more consistent when conveyed PsyCap is congruent with self-attributed PsyCap. Our work contributes to a better understanding of the underlying mechanisms that make leaders with greater conveyed PsyCap more effective and advances the conceptualization and measurement of PsyCap.

Keywords: leadership; conveyed psychological capital; positive energizing; leader effectiveness

If leaders are optimistic regarding the outcome of a project, but do not convey this optimism, the positive effects on followers may be minimized or non-existent. (Avey, Avolio, \& Luthans, 2011: 284)

Psychological capital (PsyCap), broadly defined as a higher-order construct that includes four intertwined strengths (self-efficacy, hope, optimism, and resilience), has gained attention in the organizational and management literatures for its influence on human performance. Research suggests that leaders with strong PsyCap experience lower stress and higher subjective well-being (Baron, Franklin, \& Hmileski, 2016), develop higher-quality relationships with their followers (Story, Youssef, Luthans, Barbuto, \& Bovaird, 2013), and generally perform better at work (Avey et al., 2011; Chen, 2015; Youssef \& Luthans, 2012). Given the importance of leader PsyCap, many scholars and practitioners have encouraged leaders to train and develop stronger levels of PsyCap at work (Luthans \& Youssef-Morgan, 2017; Peterson, Balthazard, Waldman, \& Thatcher, 2008).

Although research on leader PsyCap has made great progress in recent years (Luthans, Youssef-Morgan, \& Avolio, 2015), scholars have paid relatively little attention to how and through what processes a leader's PsyCap might affect his or her team members (Luthans \& Youssef-Morgan, 2017). While a handful of past research (Dawkins, Martin, Scott, \& Sanderson, 2013; Luthans \& Youssef-Morgan, 2017) has tended to examine a leader's selfattributed (i.e., self-reported) PsyCap and its downstream implications on his or her behaviors, our current work extends this literature by conceptually distinguishing between a leader's self-attributed and conveyed PsyCap (i.e., PsyCap as perceived by team members). We further explore whether the effects of a leader's conveyed PsyCap can transmit to his or her team members. Considering that leadership is a relational process (Uhl-Bien, 2006) and drawing from Van Kleef's (2009) emotions-as-social-information (EASI) model, we suggest that self-attributed PsyCap and conveyed PsyCap may have different effects on team members and that the latter should be more predictive of team member behaviors and ratings of leader effectiveness.

Briefly, the EASI model suggests that emotional expressions provide information to observers and thus exert interpersonal influence on the observers' cognitions, attitudes, and behaviors. This influence can occur through either the perceiver's emotional state or his or her cognitions and beliefs. We suggest that because conveyed leader PsyCap is likely to 


\section{Figure 1 \\ Hypothesized Model}

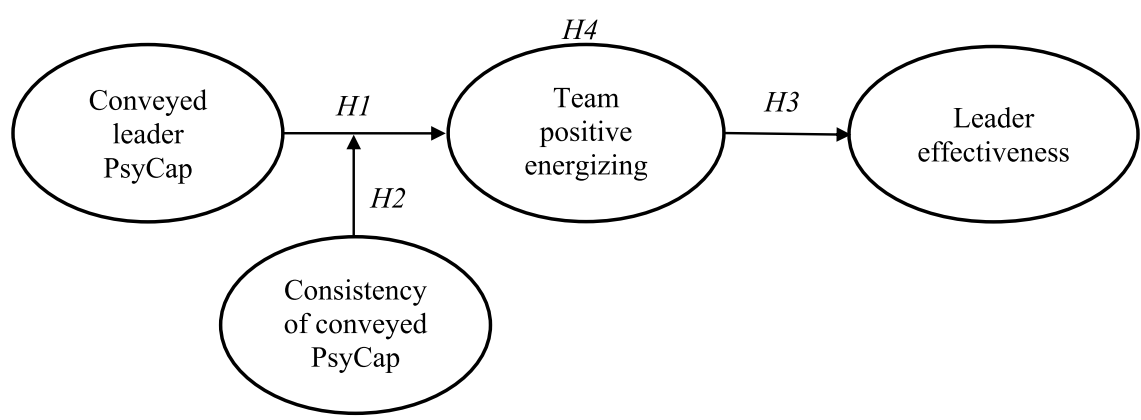

manifest in positive emotional expressions that convey a sense of confidence and optimism, it will lead to greater team positive energizing, defined as "shared experience and demonstration of positive affect, cognitive arousal, and agentic behavior among unit members in their joint pursuit of organizationally salient objectives" (Cole, Bruch, \& Vogel, 2012: 447). We further suggest that team positive energizing, in turn, increases perceptions of leader effectiveness. In short, we suggest that by conveying PsyCap to the team members, a leader acts as an "energy enhancer" for his or her team members (Schippers \& Hogenes, 2011; Vogel \& Bruch, 2012), and the leader in turn is perceived to be more effective (Owens, Baker, Sumpter, \& Cameron, 2016; Quinn, Spreitzer, \& Lam, 2012).

We further examine the moderating effect of the consistency of conveyed leader PsyCap on the relationship between conveyed PsyCap and team positive energizing. Consistent with the EASI model (Van Kleef, 2009), climate strength theory (Schneider, Salvaggio, \& Subirats, 2002), and research on differentiated leadership (Chiniara \& Bentein, 2017; Herdman, Yang, \& Arthur, 2017; Wu, Tsui, \& Kinicki, 2010), we suggest that team members take careful note of the leader's behavior toward not just themselves personally but their peers as well and react in accordance with consistently expressed attitudes and behaviors (He, Fehr, Yam, Long, \& Hao, 2017). Whereas a consistent level of conveyed leader PsyCap suggests that the leader indeed possesses strong PsyCap, an inconsistent level of conveyed PsyCap signals to team members that the leader may not in fact possess strong PsyCap but may be situationally or otherwise constrained to act as if he or she does. Consistently conveyed leader PsyCap reduces the availability of situational explanations, creating uniformity in team member perceptions and allowing for a greater impact on team positive energizing (González-Romá, Peiró, \& Tordera, 2002). In contrast, when a leader does not consistently convey his or her PsyCap to each team member, we theorize that the positive effects on team positive energizing will be weakened. Our theoretical model is depicted in Figure 1.

Our research makes several important contributions to the literature on PsyCap. First, our work is one of the first to distinguish the conceptual and examine the empirical differences between conveyed versus self-attributed leader PsyCap. Whereas self-attributed PsyCap might help leaders succeed in their own tasks, effective leadership requires leaders to convey their PsyCap to team members. Our work thus contributes to the PsyCap literature by examining its downstream consequences beyond the self. Second, by testing team positive 
energizing as the mechanism through which conveyed leader PsyCap affects ratings of leader effectiveness, our study also helps to explain why leaders with higher conveyed PsyCap are rated as more effective (Newman, Ucbasaran, Zhu, \& Hirst, 2014). Such an effort responds to calls to enrich leadership theory by illuminating the mechanisms of leadership influence (Hernandez, Eberly, Avolio, \& Johnson, 2011; Kark \& Van Dijk, 2007; Yukl, 1999). Third, our work suggests that high levels of conveyed PsyCap are not enough; it is also critical to ensure that leaders convey their PsyCap in a consistent manner to all team members. By considering both mechanisms and boundary conditions, we offer new insight into the why and when of leadership influences on performance (Colquitt \& Zapata-Phelan, 2007) and generate concrete practical implications for effective leadership. Finally, through a post hoc analysis suggesting that the congruence/discrepancy between self-attributed PsyCap and conveyed PsyCap may affect the consistency of conveyed PsyCap, our study contributes to the discussion on the nature of self- versus other-reports of leadership traits and behaviors (i.e., self-other agreement; Lee \& Carpenter, 2017).

\section{Theory and Hypotheses}

\section{Distinguishing Self-Attributed PsyCap Versus Conveyed PsyCap}

Luthans et al. (2015: 2) defined PsyCap as an individual's positive psychological state of development characterized by

(1) having confidence (efficacy) to take on and put in the necessary effort to succeed at challenging tasks; (2) making a positive attribution (optimism) about succeeding now and in the future; (3) persevering toward goals and, when necessary, redirecting paths to goals (hope) in order to succeed; and (4) when beset by problems and adversity, sustaining and bouncing back and even beyond (resilience) to attain success.

The underlying mechanism shared among these dimensions is "one's positive appraisal of circumstances and probability for success based on motivated effort and perseverance" (Luthans, Avolio, Avey, \& Norman, 2007: 550) that is best captured by the combination of the four strengths into a higher-order construct (Luthans \& Youssef-Morgan, 2017). Although past research has examined leader self-attributed PsyCap and its influence on leader behavior, we suggest that PsyCap can also be conceptualized as conveyed PsyCap and can influence followers who regularly interact with leaders. The idea of conveyed PsyCap was first introduced by Avey et al. (2011) and is reflected by how others perceive an individual's level of PsyCap.

Scholars have assumed that self-attributed PsyCap is a valid representation of how selfconfident, hopeful, optimistic, and resilient a leader is (Luthans \& Youssef-Morgan, 2017). However, the presumed accuracy and validity of self-reports rests on two basic assumptions that are not always met. The first assumption is that leaders are accurately aware of their attributes as represented in the Psychological Capital Questionnaire's (PCQ) items. The second assumption is that once leaders are cognizant of their PsyCap, they are willing and able to report it accurately. The evidence against these two assumptions has led some researchers to propose measuring PsyCap through implicit measures (Harms \& Luthans, 2012; Harms, Vanhove, \& Luthans, 2017). There are several reasons, however, why neither implicit nor self-attributed PsyCap fully capture conveyed PsyCap. 
First, leaders are constantly required to adopt impression management behaviors to deal with different aspects of their jobs (Bolino, Long, \& Turnley, 2016; Leary, 1989). In other words, leaders might adopt different impression management tactics and convey a strength that they do not actually possess as measured with self-attributed PsyCap. For example, a leader might be low in self-attributed PsyCap, but he or she at times might engage in selfpromotion behaviors to enhance perceptions of his or her self-efficacy and resilience in front of the team members, regardless of how much self-efficacy and resilience he or she actually possesses. Conversely, a leader might possess a high level of self-attributed PsyCap but might choose to convey a lower level of PsyCap to manage desirable impressions in team members. For example, a leader may avoid showing optimism about the company prospects in order to induce greater effort from his or her team members or to persuade team members about the need to implement downsizing that might otherwise be seen as punitive and unnecessary.

Second, often the leadership process unfolds within situations that are strong by nature (Dalal, Meyer, Bradshaw, Green, Kelly, \& Zhu, 2015; Meyer, Dalal, \& Hermida, 2010), such as when job demands are high, job autonomy is low ( $\mathrm{Ng}$, Ang, \& Chan, 2008), and substitutes/neutralizers of the leaders' self-attributed PsyCap may operate (Rego, Marques, Leal, Sousa, \& Cunha, 2010; see also Schriesheim, 1997). In those situations, a leader may convey behaviors that reflect more the situational requirements than his or her inner PsyCap. In other words, leader behaviors may at times be affected more by contexts than by the leader's traits (Dalal et al., 2015; Ng et al., 2008). In such situations, the expression of leaders' PsyCap might be suppressed or otherwise at odds with their dispositional tendencies. As another example, middle managers might be motivated to either enhance or suppress their expression of PsyCap to match the levels of PsyCap conveyed by senior managers. In short, contextual factors may "neutralize" the expression of a high level of self-attributed PsyCap (Rego et al., 2010).

Finally, leaders may not convey PsyCap similarly toward different team members. Consistent with research on differentiated leadership (Wu et al., 2010), a leader may exhibit varying levels of individual-focused leadership behavior to different team members. The individual differences of each team member (Harms \& Spain, 2014; Wood, Harms, \& Vazire, 2010) may also lead each follower to interpret the same leader behavior differently. In other words, conveyed PsyCap by a leader is in the "eye of the beholders" and may not necessarily represent self-attributed PsyCap.

\section{The Effects of Conveyed Leader PsyCap on Team Positive Energizing}

If there are differences between self-attributed and conveyed PsyCap, then which manifestation is most likely to predict follower behaviors? Because leadership is inherently a relational process (Fairhurst \& Uhl-Bien, 2012; Pellegrini, 2015; Uhl-Bien, 2006), what likely matters most for the impact of leaders on their team members is what the leaders convey to them and not simply what the leaders feel and believe (DeRue, 2011). Inevitably, in interactions with their team members, leaders convey affective states and beliefs to their followers ("one cannot not communicate"; Watzlawick, Beavin, \& Jackson, 1967: 49). Drawing from the EASI model (Van Kleef, 2009), we suggest that, to the extent that conveyed PsyCap is likely to manifest (or to be interpreted) through confident, positive, and energized behavioral displays (Luthans \& Youssef-Morgan, 2017), team members will use this information 
to appraise the situation positively and act energetically as a result (Van Kleef, De Dreu, \& Manstead, 2010; Van Knippenberg \& Van Kleef, 2016). In a broad sense, positive energy within a team refers to the "force that a [team] works with to purposefully put things into motion" (Vogel \& Bruch, 2012: 695). Past research suggests that positive leadership behavior is one of the best predictors of positive energizing within a team, and leaders are often referred to as "team energizers" (Bruch \& Vogel, 2011; Owens et al., 2016; Schippers \& Hogenes, 2011; Shirom, 2010; Vogel \& Bruch, 2012; Walter \& Bruch, 2010). We suggest that conveyed leader PsyCap will lead to increased positive energizing.

The central tenets of EASI are that (a) leaders' emotional expressions provide information for team members, (b) team members react to these emotional expressions through either an affect-based or a cognition-based inferential pathway, and (c) these reactions through either pathway drive behavioral changes. In order to have a high level of conveyed PsyCap, leaders must engage in PsyCap-related expressions and behaviors. Prototypical conveyed PsyCap behaviors often communicate positive affective states and cognitive information to team members. For example, in dealing with difficult work tasks, a leader high in conveyed PsyCap will have to convey both affective information that the tasks can be accomplished (e.g., by displaying positive affect and suppressing anxiety) and cognitive information of how to complete the tasks. As a result, we suggest that conveyed leader PsyCap can lead to team positive energizing through both the affect- and cognition-based pathways.

First, the affective pathway suggests that followers will be influenced by a leader's expression of PsyCap through processes of emotional contagion. Emotional contagion is the process through which individuals automatically mimic and synchronize with another's facial expressions, movements, body gestures, and vocalizations, producing emotional convergence among those who interact (Van Kleef, 2009, 2010; Van Knippenberg \& Van Kleef, 2016). A leader who conveys a high level of PsyCap positively energizes the team because the positive affect and energy associated with high levels of conveyed PsyCap (Luthans \& Youssef-Morgan, 2017; Youssef-Morgan \& Luthans, 2015) are transferred to team members through affective contagion (Bono \& Ilies, 2006; Sy \& Choi, 2013; Visser, van Knippenberg, van Kleef, \& Wisse, 2013).

Second, a leader's emotional expressions may also trigger cognition-based inferential processes among team members (Koning \& Van Kleef, 2015; Van Kleef, 2009, 2010; Van Kleef et al., 2010; Van Kleef, Homan, Beersma, van Knippenberg, van Knippenberg, \& Damen, 2009). Team members, who have lower power relative to a leader, are motivated to acquire information concerning a leader's feelings, motives, goals, and behavioral intentions (Van Kleef et al., 2010). Leader emotional expressions often convey just this sort of information (Van Kleef et al., 2009) and therefore are scrutinized by team members who have higher epistemic motivation and engage in more systematic information processing (Van Kleef et al., 2010). We therefore suggest that high levels of leader conveyed PsyCap will lead team members to infer that the leader (a) believes in his or her own capacities to handle problematic situations and seize opportunities in an effective way, (b) exerts his or her own best efforts to pursue the team goals regardless of the problems and obstacles, (c) faces the future with optimism, and (d) bounces back and recovers from failures and setbacks. In line with the core tenets of the EASI model mentioned above, we argue that this inferential process about the leader's qualities and how the leader makes sense of the situation helps team members to adopt an affectively positive, cognitively aroused, and agentic approach toward team goals, 
which captures the essence of being positively energized (Cole et al., 2012). In other words, if team members see the leader being optimistic toward a problematic situation or show resilience after a setback, they will be more likely to view challenging situations with a positive, energized perspective. In contrast, if the leader responds to challenging situations by showing signs of feeling defeated, overwhelmed, or hopeless (i.e., conveying a low level of PsyCap), these expressions are likely to produce negative affect, cognitive listlessness, or a sense of helplessness, which would deenergize the team. In light of these arguments, we propose the following:

Hypothesis 1: Conveyed leader PsyCap is positively related to team positive energizing.

\section{The Consistency of Conveyed Leader PsyCap as a Moderator}

Although we expect a positive relationship between conveyed leader PsyCap and team positive energizing, we suggest that this positive effect will be attenuated if a leader cannot consistently convey his or her PsyCap to all team members. From our discussion of how and why conveyed PsyCap might be inconsistent with self-attributed PsyCap, several reasons emerged explaining why leaders might appear inconsistent in their expressions of PsyCap. For example, situational constraints or impression management motives may produce particular emotional expressions that differ from baseline levels of conveyed PsyCap. As another example, we know that leaders often cannot or do not want to treat all team members in the same way. Research on differentiated leadership suggests that most leadership behaviors (whether positive or negative) involve some level of differentiation (Wu et al., 2010; Zhang, Li, Ullrich, \& van Dick, 2015), and to the extent that leaders engage in such differentiated observable behavior, their level of PsyCap will appear inconsistent.

Furthermore, even if leaders made efforts to convey PsyCap equally and consistently to all team members, the literature on cognitive appraisal of emotion expressions (Barsade, 2002; Van Kleef et al., 2009; Van Knippenberg \& Van Kleef, 2016) suggests that team members have unique attentional processes and epistemic motivations that could lead to different perceptions and interpretations of conveyed leader PsyCap (De Dreu, Nijstad, \& van Knippenberg, 2008). The same emotional displays may be "caught" and interpreted differently by team members holding different perceptual biases (Harms \& Spain, 2014). The result of these differentiated perceptions is that conveyed PsyCap will likely vary in its perceived consistency depending on context as well as leader and follower characteristics.

Based on the EASI model, we posit that the consistency of conveyed PsyCap moderates the relationship between conveyed leader PsyCap and team positive energizing. A basic assumption underlying the EASI model is that individuals "turn to each other's emotional expressions to make sense of ambiguous (social) situations and that such disambiguating information can be gleaned from verbal as well as nonverbal expressions" (Van Kleef, van den Berg, \& Heerdink, 2015: 1137). Considering that team members do not resort only to the information the leader conveys directly to them but they also pay attention to the information the leader conveys to other team members and react accordingly ( $\mathrm{Li}, \mathrm{He}, \mathrm{Yam}, \&$ Long, 2015; Wu et al., 2010), it is expected that the "disambiguating" process is made easier as opposed to more difficult when the conveyed PsyCap toward different team 
members is consistent versus inconsistent. Inconsistencies may lead team members to form ambiguous or mixed interpretations about the leader's PsyCap, and this ambiguity may weaken the effects of conveyed PsyCap on team positive energizing. For example, He et al. (2017) found that positive leadership behavior in the form of interactional justice does not lead to increased leader-member exchange quality when the leader cannot consistently deliver the interactional justice to all team members. The assumption is that when a positive leadership behavior (e.g., conveyed PsyCap, justice, etc.) is differentially applied to team members, team members attribute such leadership behaviors not to the leader's dispositions but rather to situational demands, thus diminishing the positive effects (GonzálezRomá, et al., 2002; Schneider et al., 2002; Zohar \& Luria, 2004). Even when a team leader conveys high levels of PsyCap, a high level of inconsistency will create uncertainty about underlying levels of PsyCap, minimizing its energizing impact. Hence we hypothesize the following:

Hypothesis 2: The within-team consistency of conveyed leader PsyCap moderates the relationship between conveyed leader PsyCap and team positive energizing such that the relationship is stronger when the consistency is higher versus lower.

\section{Downstream Consequences on Leadership Effectiveness}

We suggest that team positive energizing, as a result of high conveyed leader PsyCap, will lead to increased leadership effectiveness. Following past research (Van Knippenberg \& Van Kleef, 2016), we define leadership effectiveness as the leader's success in mobilizing and motivating team members for collective goals. Team positive energizing predicts leadership effectiveness because positive energy is a key motivational force (Marks, 1977; Quinn \& Dutton, 2005) in that it increases team members' capacity for action and motivation, enabling them to do their work more effectively and attain team goals (Owens et al., 2016; Quinn et al., 2012). As a motivational force, positive energizing contributes to the intensity and persistence of effort of team members toward team goals (Quinn \& Dutton, 2005). It also fosters team member motivation and engagement and provides psychological resources to overcome challenges that stand in the way of team performance (Baker, Cross, \& Wooten, 2003; Morgeson, DeRue, \& Karam, 2010; Owens et al., 2016; Quinn \& Dutton, 2005). In sum, leaders who are more able to positively energize their team members (such as leaders high in conveyed PsyCap) are more effective as team leaders (Cross \& Parker, 2004). Hence we hypothesize the following:

Hypothesis 3: Conveyed leader PsyCap has an indirect, positive relationship with leadership effectiveness via the mediating effects of team positive energizing.

Combining our first three hypotheses, we propose a first-stage moderated mediation hypothesis:

Hypothesis 4: The indirect effect of conveyed leader PsyCap on leadership effectiveness via team positive energizing is moderated by the within-team consistency of conveyed leader PsyCap such that the indirect effect is stronger when within-team consistency is high but dissipates when within-team consistency is low. 


\section{Research Overview}

We conducted two studies to test our hypotheses. To establish causal validity between conveyed leader PsyCap and team positive energizing and to increase the cross-cultural validity of our work, our first study tested Hypotheses 1 and 2 experimentally through a vignette-based experiment in the United States. After establishing causal inferences in Study 1, we conducted a multisource Study 2 in the field in Portugal to test our full theoretical model.

\section{Study 1}

\section{Participants and Procedure}

We contacted 500 full-time employees from a diverse range of industries to participate in this research through Qualtrics, a third-party online survey administration company in the United States (for a recent example of data collection using Qualtrics, see Yam, Christian, Wei, Liao, \& Nai, in press). In our initial contact with the participants, we provided a general overview of the research (e.g., a leadership study) but did not disclose any specific research hypotheses. A total of 165 participants completed the study $\left(M_{\text {age }}=38.35,57.6 \%\right.$ female, $50.3 \%$ Caucasian). We compensated each participant with US\$5.00.

\section{Manipulations}

Conveyed leader PsyCap manipulation. We told all participants to read a vignette carefully and imagine themselves working with the leader described. In the high-conveyedleader-PsyCap condition, we described the leader using items adapted from the PCQ (Avey et al., 2011). Specifically, we picked items from each of the four PsyCap dimensions in order to manipulate conveyed leader PsyCap. For example, in the high-PsyCap condition we told participants that the leader "believes in his ability and capacity to represent his work area in meetings with top management" (self-efficacy) and "he can get through difficult times at work because he has experienced difficulty before" (resilience). Following past vignette-based leadership research, we used transactional leadership in the control condition (van Dierendonck, Stamn, Boersma, de Windt, \& Alkema, 2014), because transactional leadership is relatively neutral in terms of PsyCap and this procedure is therefore empirically more conservative than if we had adopted a scenario where conveyed PsyCap was explicitly low. Similar manipulations of leadership have been used in prior research (Rego et al., 2017). All scenarios used can be found in the online supplement.

Consistency of conveyed leader PsyCap manipulation. Given that we conceptualized consistency of conveyed leader PsyCap as a leader's differential social interactions with his or her team members in terms of conveyed PsyCap, we followed the differentiated leadership literature (e.g., Wu et al., 2010) and manipulated consistency of conveyed PsyCap by emphasizing the extent to which the leader selectively treats his or her team members in different ways. In the high-consistency condition, we told participants that the leader treats all his team members the same way. In the low-consistency condition, we told participants that the leader treats some of his employees this way but others differently. 


\section{Measures}

Follower team positive energizing. We measured team positive energizing with three items adapted from Atwater and Carmeli (2009) and Cole et al. (2012). We asked participants to imagine how they would think and feel if they were to work for the hypothetical leader named John. The items are "John has energy that rubs off on team members," "Team members have more will to work when John is present," and "Whenever his team members may be unmotivated, John is able to lift their spirits and get them moving" $(M=5.21, S D=1.52, \alpha=.87)$.

Manipulation checks. At the end of the study, we asked participants to what extent did they think John is (a) self-confident, (b) optimistic, (c) perseverant, and (d) resilient as a manipulation check $(M=5.70, S D=1.31, \alpha=.90)$. We replaced hopeful with perseverant because perseverant is more easily connected to leader actions than hopeful and does not alter the underlying meaning of that particular dimension. As expected, participants in the high-PsyCap condition reported the leader to convey higher levels of PsyCap $(M=5.98, S D$ $=1.12)$ compared to participants in the control condition $(M=5.42, S D=1.43), t(163)=$ $2.84, p<.01, d=.44$, suggesting that our manipulation was successful.

\section{Results}

Participants in the high-conveyed-PsyCap condition reported higher levels of team positive energizing $(M=5.56, S D=1.41)$ compared to participants in the low-PsyCap condition $(M=$ $4.87, S D=1.55), t(163)=3.00, p<.01, d=.45$. This result supports Hypothesis 1 . Hypothesis 2 predicted an interactive effect of conveyed leader PsyCap and consistency of conveyed PsyCap on team positive energizing. Results suggested that the interaction term was significant $(\beta=.27), t(164)=2.05, p=.04$, and predicted significantly more variance compared to a base model without the interaction term (adjusted $R^{2}=.08 ; \Delta R^{2}=.02, p=.04$ ). Simple slopes analysis further confirmed that the effect of conveyed leader PsyCap on team positive energizing was significant when consistency was high $(t=4.49, p<.01)$ but was not significant when consistency was low $(t=1.21, p=.23$; Figure 2$)$. These results supported Hypothesis 2 .

\section{Discussion}

Study 1 supported that a leader who conveys high PsyCap positively energizes his or her team members and that such an effect is stronger when the leader is consistent toward all team members in conveying his or her PsyCap. Although Study 1 provides initial evidence to support our theoretical model, a vignette design is arguably artificial, and thus we conducted a multisource field study to examine the effects of leader conveyed PsyCap on leader effectiveness through team positive energizing. Another goal of Study 2 is to provide some empirical evidence in support of the distinction between conveyed and self-attributed PsyCap by controlling for self-reported leader PsyCap in all analyses.

\section{Study 2}

\section{Sample and Procedures}

The sample comprised 110 midlevel managers $\left(M_{\text {age }}=37.05,82.7 \%\right.$ male, $\left.S D=4.21\right)$ from 71 organizations operating in various sectors (e.g., energy, consulting, software, 
Figure 2

How the Level of Conveyed Leader Psychological Capital Interacts With the Respective Consistency (Within the Team) to Predict Team Positive Energizing (Study 1)

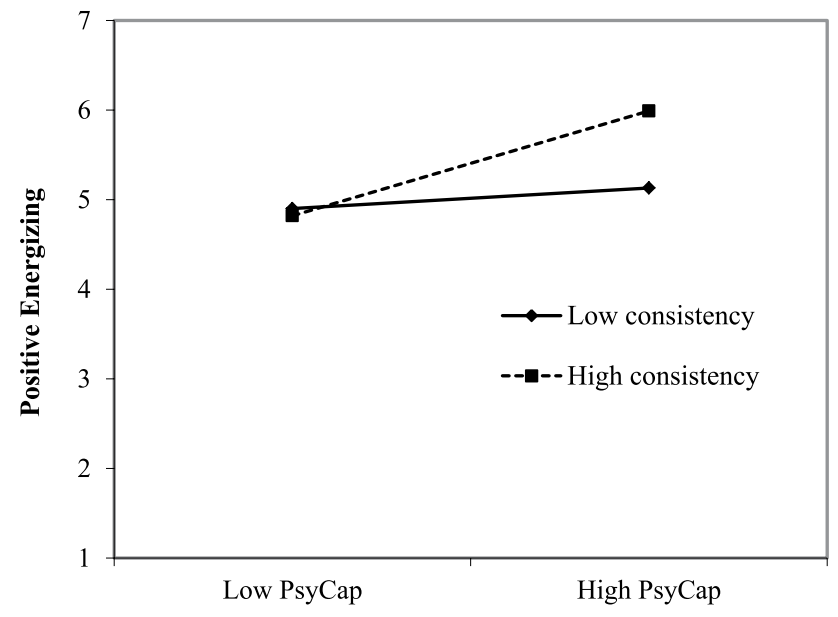

telecommunications, electronics, pharmaceutical and health care, banking, and retailing), their direct supervisors (i.e., 110 senior managers), and 368 of their subordinates. The midlevel managers were participants in a leadership development program conducted in an MBA program. Embedded within the program was a 360-degree feedback exercise covering several variables, including those in our model. The exercise was completed on a secure web platform. In this study, subordinates rated the conveyed PsyCap of their leaders and team positive energizing (sample split: data for each variable from different team members; see below) and the direct supervisors of the middle-level managers rated leader effectiveness. The midlevel managers self-reported their PsyCap as a control variable.

The midlevel managers were given instructions for selecting subordinates: (a) They should choose diverse subordinates with whom they had frequent positive and less positive relationships, and (b) the length of the working relationship with the informant should be at least 6 months. To assure subordinates that anonymity was preserved, we informed them that only data from at least two subordinates were to be considered. Given our focus on team energizing and within-team consistency of conveyed PsyCap, we included only data from midlevel managers who had at least three subordinate ratings. Midlevel managers who did not obtain sufficient subordinate ratings were removed from the data, resulting in a final midlevel manager sample size of $68\left(M_{\text {age }}=38.06,83.8 \%\right.$ male, $\left.S D=4.33\right)$. No significant differences were found between the initial sample versus the final one in terms of selfreported and conveyed PsyCap, positive energizing, and leader effectiveness ( $t$ test ranges between -.05 and $.78, p>.43$ ). The direct supervisors and the subordinates of the midlevel managers (and the midlevel managers themselves), were asked to report (on a 7-point Likert scale) the degree to which the statements applied to the target leader (or, for the leaders themselves): 1 = the statement does not apply to this leader (to me) at all to $7=$ the statement applies completely to this leader (to me). Data for conveyed leader PsyCap and team positive energizing were aggregated at the team level. In sum, leaders reported their PsyCap as a 
control variable, team members reported on conveyed leader PsyCap and team positive energizing, and the leaders' own supervisors rated the leaders' effectiveness.

\section{Measures}

Conveyed PsyCap and self-attributed PsyCap. Twelve items for measuring self-efficacy, hope, optimism, and resilience (three items per dimension) were adapted from Parker (1998); Snyder, Sympson, Ybasco, Border, Babyak, and Higgins (1996); Scheier, Carver, and Bridges (1994); and Wagnild and Young (1993). Sample items are (a) "Feels confident when searching for a solution to a long-term problem" (self-efficacy), (b) "When in a difficult situation at work, thinks of many ways to solve it" (hope), (c) "With regard to his/her work, he/she is optimistic about what will happen to him/her in the future" (optimism), and (d) "When having a setback at work, finds it easy to recover and move forward" (resilience). We aimed at having a manageable measure (i.e., short) within a 360-degree feedback exercise covering a wide range of variables. Taking theoretical and empirical evidence into account (Luthans \& Youssef-Morgan, 2017; Newman et al., 2014), we conducted confirmatory factor analyses (CFA) to test a second-order factor model in which the scores of each dimension are considered indicators of the higher-order construct. The model fit the subordinates' (aggregated; see below for justification) data well, $\chi^{2}(50)=59.33, p>.05$, root mean square error of approximation $(\mathrm{RMSEA})=.05$, goodness-of-fit index $(\mathrm{GFI})=.89$, comparative fit index $(\mathrm{CFI})$ and incremental fit index $(\mathrm{IFI})=.98$, but represented a mediocre fit to the self-reported data, $\chi^{2}(50)=65.45, p<.01, \mathrm{RMSEA}=.07, \mathrm{GFI}=.88, \mathrm{CFI}=.88, \mathrm{IFI}=.90$. Consistent with the poorer model fit, the reliabilities of the global PsyCap measures exhibited a similar pattern ( $\alpha=.91$ and .69, for conveyed PsyCap and self-reported PsyCap, respectively). As our primary hypotheses concerned conveyed rather than self-attributed PsyCap, we moved forward with the use of the 12-item Conveyed PsyCap measure (see online supplement for complete scale). We retained the measure of self-attributed PsyCap for the purposes of exploration and as a potentially useful control variable but have been cautious in drawing inferences based on its use, given its tenuous measurement properties.

Team positive energizing. Team positive energizing $(\alpha=.94)$ was measured with the same items as in Study 1.

Leadership effectiveness. Leader effectiveness $(\alpha=.86)$ was rated by the leaders' supervisors and measured with three items developed specifically for the 360-degree feedback exercise. The items were (a) "Makes a strong contribution to the effectiveness of his/her team members," (b) "His/her team members produce good work as a result of his/her actions," and (c) "The way he/she acts is crucial to his/her team's effectiveness."

Consistency of conveyed PsyCap. The standard deviation of individual scores within each team was calculated to measure the consistency of the PsyCap conveyed toward the team. We followed LeBreton and Senter (2008), who suggested that standard deviation "is ideally suited for testing dispersion composition models" (p. 820; see also Herdman et al., 2017). The standard deviation score was reversed (by subtracting it from 1.64, this score representing the team with the highest standard deviation), allowing the resulting score to be named consistency of conveyed PsyCap (higher scores represent greater consistency). 


\section{Aggregating Data at the Leader/Team Level}

For testing whether it was appropriate to aggregate data at the leader/team level (conveyed leader PsyCap and positive energizing as rated by subordinates), intraclass correlation (ICC) (1), ICC(2), and $r_{w g(J)}$ were estimated. The $r_{w g(J)}$ values relative to the uniform distribution were .94 (i.e., very strong agreement; LeBreton \& Senter, 2008) for conveyed leader PsyCap and .84 (strong) for positive energizing. When the slightly skewed distribution was considered, the $\mathrm{r}_{\mathrm{wg}(\mathrm{J})}$ values were .91 (i.e., very strong agreement) and .77 (strong), respectively. ICC(1) values were .28 (large effect; LeBreton \& Senter, 2008) and .27 (large), also respectively. ICC(2) values were .61, and .62, also respectively. These values clearly justified aggregation.

Although these aggregation indices provide evidence of significant cluster effects in our data, our model was hypothesized only at the team level of analysis. Consequently, we did not examine a multilevel model, but did adjust standard errors for path coefficients to take the nonindependence of the data into account using the TYPE=COMPLEX procedure within Mplus. We did not, however, use this procedure when calculating and testing our indirect effects (i.e., H3 and H4), as TYPE=COMPLEX does not currently provide more accurate bootstrapped estimates of indirect effects (cf. MacKinnon, Lockwood, \& Williams, 2004).

\section{Reducing Risks of Common Method Variance}

To reduce the risks of common method variance, we adopted the following procedures. First, leader effectiveness was measured with data from leaders' direct supervisors $(n=68)$. The extant literature (e.g., Amundsen \& Martinsen, 2014; Judge \& Bono, 2000; Seibert, Sargent, Kraimer, \& Kiazad, 2016) has frequently promoted the use of supervisor ratings to rate a leader's effectiveness, as superiors normally have responsibility for evaluating their subordinates' effectiveness for performance appraisal and promotion proposals. Second, each set of subordinate responses was randomly split into two subsamples, with one subsample being aggregated and used to measure conveyed leader PsyCap and the other subsample aggregated to measure positive energizing (Kozlowski, Mak, \& Chao, 2016; Ostroff, Kinicki, \& Clark, 2002). Consequently, both variables reflected team perceptions but were taken from different members of each team. This procedure proved to be appropriate: The relationship between the two variables is much stronger when the respective data proceed from the same subordinates $(r=.85, p<.01)$ than when they come from different raters $(r=$ $.40, p<.01)$.

\section{Results}

Table 1 presents means, standard deviations, and correlations. Conveyed leader PsyCap does not correlate with self-attributed PsyCap, a fact that we examine and discuss later. As expected, conveyed leader PsyCap positively correlates with team positive energizing and leader effectiveness. The consistency of conveyed PsyCap correlates positively with team positive energizing, and team positive energizing correlates positively with leader effectiveness.

To test for Hypotheses 1 and 2, we conducted hierarchical ordinary least squares regression analyses (with adjusted estimation as mentioned earlier). Whereas self-attributed PsyCap 
Table 1

Means, Standard Deviations, and Correlations (Aggregated Data)

\begin{tabular}{|c|c|c|c|c|c|c|}
\hline Variable & $M$ & $S D$ & 1 & 2 & 3 & 4 \\
\hline 1. Self-attributed PsyCap & 5.54 & .51 & - & & & \\
\hline 2. Conveyed PsyCap & 5.44 & .68 & .07 & - & & \\
\hline 3. Consistency of conveyed PsyCap & 1.05 & .31 & .01 & .05 & - & \\
\hline 4. Team positive energizing & 4.91 & .97 & .15 & $.40 * *$ & $.43^{* *}$ & - \\
\hline $\begin{array}{l}\text { 5. Leader effectiveness (rated by the } \\
\text { supervisor of the team leader) }\end{array}$ & 5.25 & .91 & .19 & $.28^{*}$ & .14 & $.34 * *$ \\
\hline
\end{tabular}

Note: $N=68$ leaders/teams. The values for conveyed PsyCap and positive energizing proceed from two different samples of subordinates who rated each leader. PsyCap $=$ psychological capital.

$* p<.05$.

$* * p<.01$.

does not predict team positive energizing (Estimate $=.12, S E=.15, p=.40$ ), conveyed PsyCap significantly predicts unique variance of team positive energizing (Estimate $=.51$, $S E=.09, p<.01)$. Thus, H1 is supported. We then examined the interacting effect of conveyed leader PsyCap and consistency of conveyed leader PsyCap on team positive energizing. As expected, the interaction term was significant (Estimate $=1.02, S E=.49, p<.05$ ). Thus, $\mathrm{H} 2$ is supported.

For a better understanding of the interaction pattern between conveyed PsyCap and the consistency of conveyed PsyCap, we tested the simple effects at two levels of consistency ( \pm 1 standard deviation of the mean). Figure 3 suggests that conveyed PsyCap does not significantly predict positive energizing when the consistency of conveyed PsyCap is low $(B=$ $.27, S E=.65, \beta=.13, t=.42, p=.68)$ but significantly predicts positive energizing when the consistency is high $(B=1.22, S E=0.30, \beta=.79, t=4.13, p<.01)$. Importantly, these results hold even after controlling for leader self-attributed PsyCap, thus providing incremental validity for the importance of leader conveyed PsyCap.

To test Hypothesis 3, we conducted bias-corrected bootstrap analyses with the PROCESS macros (Hayes, 2013; Model 4; with self-attributed PsyCap as a control). Although the direct effect of conveyed PsyCap on leader effectiveness was not significant (effect $=.22, S E=.17$, $p=.19$, confidence interval $[\mathrm{CI}]=[-.11, .55])$, the indirect effect (i.e., via increased positive energizing) was significant (effect $=.13, S E=.08, \mathrm{CI}=[.02, .32])$. Therefore, Hypothesis 3 is supported.

To test Hypothesis 4, we also conducted bias-corrected bootstrap analyses with the PROCESS macros (Model 7; with self-attributed PsyCap included as control; Table 2). As expected, the simple two-way interaction term (conveyed PsyCap x consistency of conveyed PsyCap) was a significant predictor (effect $=1.01, p<.05, S E=.50, \mathrm{CI}=[0.02,2.01])$ of team positive energizing. We further examined the full moderated mediation. Whereas the mediated relationship was not significant when consistency of conveyed PsyCap was low (effect $=.05, S E=.06, \mathrm{CI}=[-.03, .25])$, the mediated relationship was significant when consistency of conveyed PsyCap was high $(\mathrm{effect}=.20, S E=.10, \mathrm{CI}=[.03, .42])$. The index of moderated mediation is also significant (effect $=.25, S E=.15, \mathrm{CI}=[.03, .63])$, suggesting that the two conditional indirect effects differed significantly. Thus, Hypothesis 4 is supported. 
Figure 3

How the Level of Conveyed Leader Psychological Capital Interacts With the Respective Consistency (Within the Team) to Predict Team Positive Energizing (Study 2)

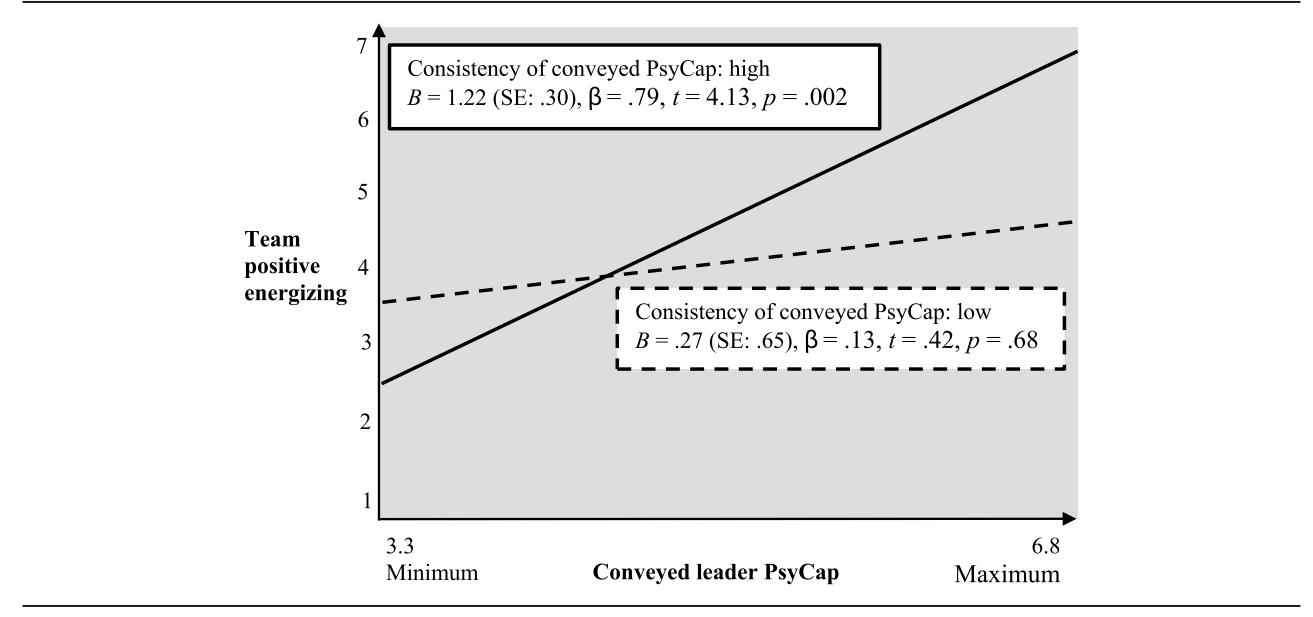

\section{Post Hoc Examination of Self-Attributed and Conveyed PsyCap}

Following the literature on self-other agreement of leadership (Fleenor, McCauley, \& Brutus, 1996; Fleenor, Smither, Atwater, Braddy, \& Sturm, 2000; Lee \& Carpenter, 2017; Ostroff, Atwater, \& Feinberg, 2004), we explored if the agreement/discrepancy between selfattributed PsyCap and conveyed PsyCap predicts the consistency of conveyed PsyCap. We first found that more than $70 \%$ of leaders have a level of self-attributed PsyCap that is discrepant from the levels of conveyed PsyCap (discrepancy computed according to Fleenor et al., 1996; see also Shanock, Baran, Gentry, Pattison, \& Heggestad, 2010), a finding consistent with our view that the two variables are conceptually different. We then explored whether a discrepancy in self-attributed versus conveyed PsyCap will affect the consistency of conveyed PsyCap directed toward followers.

To explore such a possibility, we used polynomial regression with a response surface analysis (Edwards \& Parry, 1993; Shanock et al., 2010). ${ }^{1}$ The findings (Figure 4; polynomial regression and surface tests available in the online supplement) provide some support for our arguments. The negative curvature $(a 4: B=-.38, p<.05 ; S E=.18)$ along the line of discrepancy $(x=-y)$ indicates that consistency of conveyed PsyCap decreases when the discrepancy between self-attributed PsyCap and conveyed PsyCap increases.

\section{General Discussion}

Our results suggest that a leader's conveyed PsyCap predicts team positive energizing and that this relationship is stronger when the leader is consistent toward all team members in conveying his or her PsyCap. Study 2 furthermore suggests that a leader's conveyed PsyCap has an indirect effect on leader effectiveness through team positive energizing. All these results held after controlling for self-attributed PsyCap, suggesting that self-attributed and conveyed leader PsyCap are indeed distinct constructs and that conveyed PsyCap predicts 


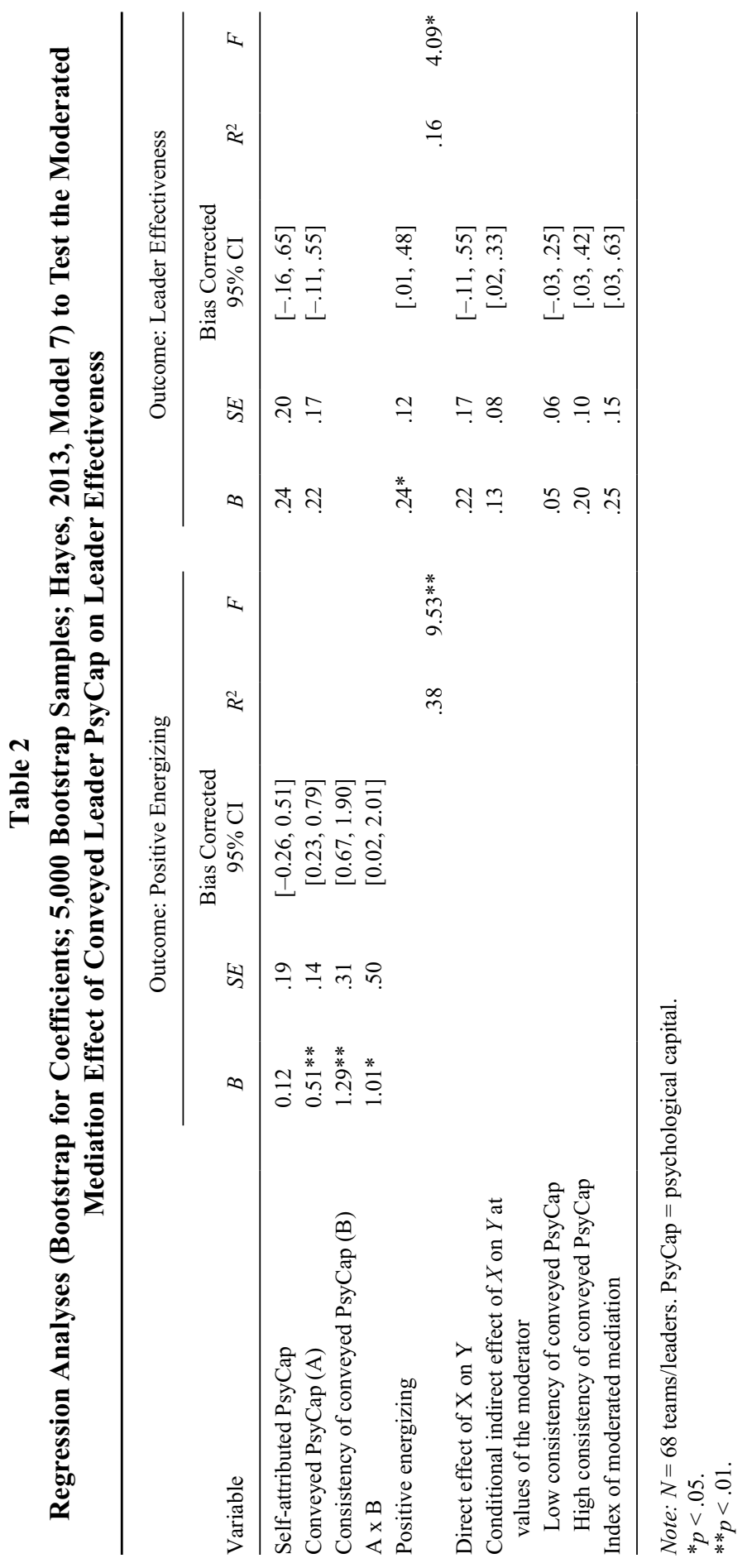


Figure 4

Surface Analysis: Consistency of Conveyed PsyCap as Predicted by the Discrepancy/ Agreement Between Self-Attributed PsyCap and Conveyed PsyCap (Study 2)

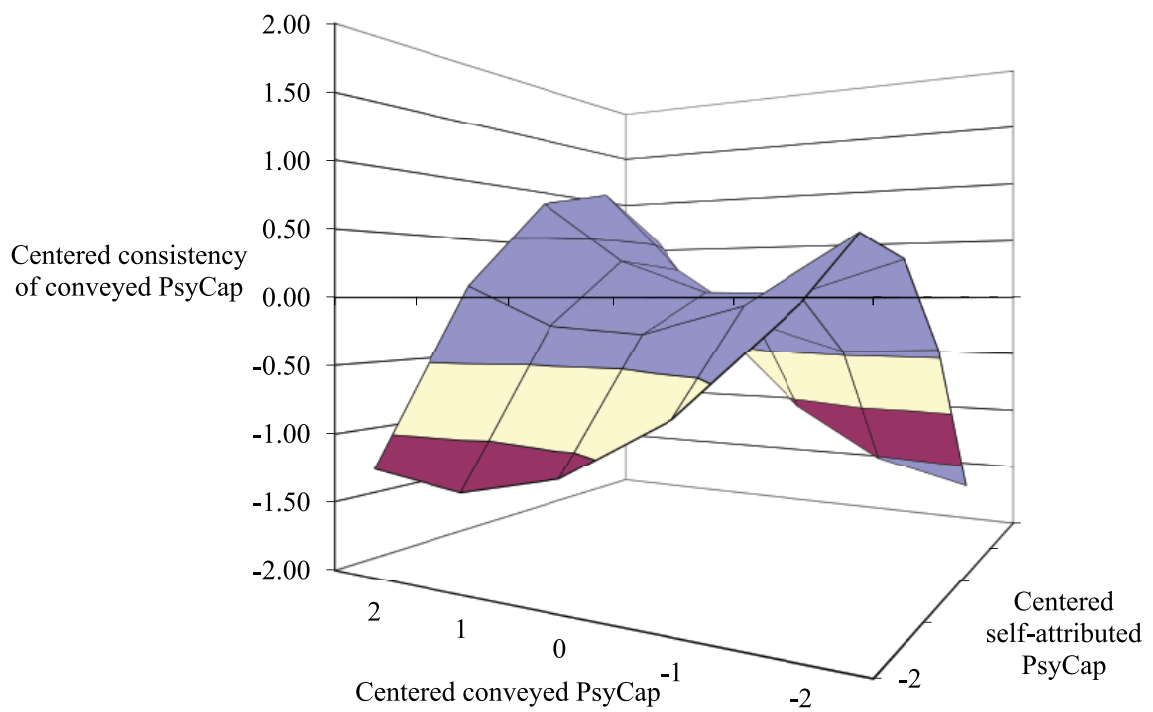

leader effectiveness above and beyond the impact of self-attributed PsyCap. Whereas past research suggests that self-attributed PsyCap might be beneficial for leaders (Avey et al., 2011; Chen, 2015; Youssef \& Luthans, 2012), our work suggests that mere high levels of PsyCap would not translate into better leadership; leaders must successfully and consistently convey their PsyCap to team members. Further, a discrepancy between leaders' self-attributed PsyCap and conveyed PsyCap may make them less able to be consistent in conveying PsyCap towards all team members (see post hoc analysis). Considering that inconsistency in conveyed PsyCap attenuates the positive effect of conveyed PsyCap on team positive energizing, our findings suggest that discrepancy between self-attributed PsyCap and conveyed PsyCap indirectly damages the capacity of leaders to positively energize the team.

\section{Theoretical Contributions}

Our study makes several important contributions. First, we are one of the first to conceptually and empirically distinguish self-attributed PsyCap and conveyed PsyCap. Several findings corroborate our theoretical arguments in favor of such a differentiation. Most leaders in our sample have a level of self-attributed PsyCap that is discrepant from their conveyed PsyCap. The nonsignificant relationship between self-attributed PsyCap and conveyed PsyCap points in the same direction and corroborates Roberts, Harms, Smith, Wood, and Webb (2006: 325), who argued that (a) "the convergence of self-reports and observer ratings of personality and other phenomena has never been as high as one would hope" and that (b) while selfreports represent the individual's identity, observer ratings represent the 
individual's reputation. Lee and Carpenter (2017) also argued that "perhaps, self-ratings and observer ratings of work behaviors are actually tapping into different constructs and should be viewed as nonequivalent measures." In other words, we suggest that conveyed leader PsyCap is in the "eye of the beholders" and does not necessarily represent either the inner (i.e., implicit and self-reported) PsyCap or what the leader actually possesses. Team members have unique attentional processes and epistemic motivations (De Dreu et al., 2008; Van Kleef et al., 2015), and different team members hold different "perceptual biases" (Harms \& Spain, 2014) and receive the same PsyCap "messages" differently (Humphrey, Burch, \& Adams, 2016).

Second, by showing that it is conveyed leader PsyCap, not self-attributed PsyCap, that predicts leader effectiveness through team positive energizing, our research extends the literature on how scholars should conceptualize PsyCap (Dawkins et al., 2015; Luthans \& Youssef-Morgan, 2017). We provide theoretical and empirical evidence suggesting that conveyed PsyCap is worth studying, at least within the relational process that characterizes leadership (Fairhurst \& Uhl-Bien, 2012; Uhl-Bien, 2006). What matters most for the influence of leaders on team members is the strengths that the leader conveys toward team members rather than merely the strengths the leader possesses.

However, post hoc analysis also suggests that the level of PsyCap a leader possesses is not irrelevant for how the leader behaves toward his or her teams. A leader who conveys a level of PsyCap that is incongruent with his or her level of self-attributed PsyCap may experience difficulties in conveying PsyCap consistently or convincingly toward all team members, and this inconsistency may attenuate the positive effect of his or her high conveyed PsyCap on team positive energizing and, in turn, reduce his or her effectiveness as a leader. In short, what our study suggests is twofold: (a) A leader is more able to energize positively the team and thus more effective if he or she conveys a high level of PsyCap consistently toward all team members, and (b) such an endeavor is easier if such a leader is provided with a high level of self-attributed PsyCap.

Third, we clarify why and when PsyCap in leaders predicts their effectiveness. By demonstrating that the relationship between conveyed leader PsyCap and leader effectiveness is mediated via team positive energizing, we respond to a call from Newman et al. (2014: S131), who argued that research focused on potential mediators of the PsyCap-outcomes relationship "is still very much in its infancy" and "more research is needed to help us understand the underlying mechanisms through which PsyCap influences workplace outcomes (at different levels of analysis)." By further demonstrating that the relationship between conveyed leader PsyCap and leader effectiveness, via team positive energizing, is moderated by the consistency of conveyed leader PsyCap, we clarify the boundary conditions for the impact of conveyed leader PsyCap on teams (Luthans \& Youssef-Morgan, 2017). Empirical demonstrations of the mechanisms, and the boundary conditions, by which positive leadership influences performance are critical components of theory building (Colquitt \& ZapataPhelan, 2007; Luthans \& Youssef-Morgan, 2017).

Fourth, our research also contributes to the literature on team/organizational energy in that the antecedents of team positive energy remain largely untested. Most research on energy in organizations has been carried out at the individual level (Vogel \& Bruch, 2012). Considering that energy is a critical organizational resource (Owens et al., 2016) and that, increasingly, organizational work is carried out within teams and by teams, our focus on how leaders energize teams provides a more thorough understanding of energy in teams 
and organizations (Spreitzer, Sutcliffe, Dutton, Sonenshein, \& Grant, 2005; Vogel \& Bruch, 2012). Our study corroborates research that frames leaders as "energy brokers" who energize their team members through interactions and relationships (Owens et al., 2016; Uhl-Bien, 2006).

\section{Limitations and Future Research Directions}

The paper is not without limitations. Both studies contain limitations that require further discussion. Although Study 1 provides causal evidence to our model, it was carried out through scenarios and thus might be low in external validity. Likewise, Study 2 also suffers from several limitations. For example, the data being collected in the context of a leadership development program might be biased in that the leaders who participated in the study may not represent the average leader. Future studies should include larger samples and test if the evidence found here can be replicated in teams operating in different sectors, carrying out different kinds of tasks, or situated at different hierarchical levels. The second limitation is that team members were not randomly selected. It might be possible that team members who like their leaders were more likely to participate and hence might inflate the ratings of conveyed leader PsyCap. Third, whereas supervisor ratings of leader effectiveness were employed in the current study, future studies should also measure leader effectiveness through more objective data, such as team members' annual evaluation of the leaders.

Fourth, while it is clear that there is a discrepancy between a leader's self-attributed and conveyed PsyCap, we recommend future studies to examine the sources of such discrepancies. For example, such a discrepancy could be due to (a) unique characteristics of the receivers (e.g., epistemic motivation; Van Knippenberg \& Van Kleef, 2016; Visser et al., 2013), (b) differentiated leadership behaviors (Wu et al., 2010), or (c) contextual constraints that inhibit the display of leader PsyCap. Relatedly, in this study we examined only the differences between conveyed versus self-attributed PsyCap, but scholars have proposed other forms of PsyCap, such as implicit and unconscious PsyCap (measured through implicit/projective measures; Harms et al., 2017; Harms \& Luthans, 2012). Future studies should test if the relationship between implicit PsyCap and conveyed PsyCap is stronger than the relationship between self-attributed PsyCap and conveyed PsyCap. Studying PsyCap along the three conceptualizations (implicit, self-attributed, and conveyed) may bring more clarity to the field and has implications for theory and practice (Harms et al., 2017; Harms \& Luthans, 2012; Luthans \& Youssef-Morgan, 2017).

Fifth, future studies should test how PsyCap conveyed toward different/specific targets differentially predicts their reactions. For example, PsyCap conveyed toward peers may ignite the peers' attitudinal, emotional, or behavioral reactions, but not necessarily the team members', unless the team also "catches" or observes that conveyed PsyCap. In addition, future work might consider if conveying PsyCap can be depleting for leaders, especially if consistently displayed toward multiple targets (i.e., subordinates, peers, and supervisors). A final limitation is that our measure of PsyCap is different from another established measure of PCQ-24 (Luthans et al., 2015), and this may explain the modest measurement properties of self-attributed PsyCap. Future studies should therefore replicate and extend our findings using other established measures. 


\section{Conclusion}

Our study brings "granularity" to the field of PsyCap. Whereas self-attributed PsyCap might be beneficial in examining the downstream consequences for a leader's own behaviors, conveyed PsyCap, when displayed consistently, has better predictive power of how a leader's PsyCap can affect team members and in turn his or her own leadership effectiveness.

Our study also has implications for practice. It is widely recognized that the performance of individuals, teams, and organizations depends not only on economic, intellectual, and social capital but also on several psychological capabilities that can be measured, developed, expanded, and utilized as resources (Luthans \& Youssef-Morgan, 2017). Our study supports this premise. Leaders who convey superior PsyCap toward the team have a more energized team and, thus, are more effective leaders. Leaders must therefore not only develop their PsyCap but must also make efforts to convey their PsyCap in a consistent manner with all team members. Leaders are more likely to convey greater PsyCap consistently toward all team members if they, themselves, have a high level of attributed PsyCap. And by conveying greater PsyCap consistently, they are more able to energize their teams, which in turn fosters perceptions of leadership effectiveness. In contrast with other forms of energy, which are depleted when expended, energy generated through interpersonal relationships "is enhanced and renewed when used" (Owens et al., 2016). Through conveying PsyCap consistently within the team, leaders will be more able to effectively mobilize and leverage the talent and energy of their team members.

\section{Note}

1. We are particularly grateful to Daniel J. Beal, the action editor, for suggesting this post hoc analysis.

\section{References}

Amundsen, S., \& Martinsen, Ø. 2014. Self-other agreement in empowering leadership: Relationships with leader effectiveness and subordinates' job satisfaction and turnover intention. Leadership Quarterly, 4: 784-800.

Atwater, L., \& Carmeli, A. 2009. Leader-member exchange, feelings of energy and involvement in creative work. Leadership Quarterly, 20: 264-275.

Avey, J. B., Avolio, B. J., \& Luthans, F. 2011. Experimentally analyzing the impact of leader positivity on follower positivity and performance. Leadership Quarterly, 22: 282-294.

Baker, W., Cross, R., \& Wooten, M. 2003. Positive organizational network analysis and energizing relationships. In K. Cameron, J. Dutton, \& R. Quinn (Eds.), Positive organizational scholarship: Foundations of a new discipline: 328-342. San Francisco: Berrett-Kohler.

Baron, R. A., Franklin, R. J., \& Hmileski, K. M. 2016. Why entrepreneurs often experience low, not high, levels of stress. Journal of Management. Advance online publication. doi:10.1177/0149206313495411

Barsade, S. G. 2002. The ripple effect: Emotional contagion and its influence on group behavior. Administrative Science Quarterly, 47: 644-675.

Bolino, M., Long, D., \& Turnley, W. 2016. Impression management in organizations: Critical questions, answers, and areas for future research. Annual Review of Organizational Psychology and Organizational Behavior, 3: 377-406.

Bono, J. E., \& Ilies, R. 2006. Charisma, positive emotions and mood contagion. Leadership Quarterly, 17: $317-334$.

Bruch, H., \& Vogel, B. 2011. Fully charged: How great leaders boost their organization's energy and ignite high performance. Boston: Harvard Business Review Press.

Chen, S.-L. 2015. The relationship of leader psychological capital and follower psychological capital, job engagement and job performance: A multilevel mediating perspective. International Journal of Human Resource Management, 26: 2349-2365. 
Chiniara, M., \& Bentein, K. 2017. The servant leadership advantage: When perceiving low differentiation in leadermember relationship quality influences team cohesion, team task performance and service OCB. Leadership Quarterly. Advance online publication. doi.org/10.1016/j.leaqua.2017.05.002

Cole, M. S., Bruch, H., \& Vogel, B. 2012. Energy at work: A measurement validation and linkage to unit effectiveness. Journal of Organizational Behavior, 33: 445-467.

Colquitt, J. A., \& Zapata-Phelan, C. P. 2007. Trends in theory building and theory testing: A five-decade study of the Academy of Management Journal. Academy of Management Journal, 50: 1281-1303.

Cross, R., \& Parker, A. 2004. Charged up: Creating energy in organizations. Journal of Organizational Excellence, 23: 3-14.

Dalal, R. S., Meyer, R. D., Bradshaw, R. P., Green, J. P., Kelly, E. D., \& Zhu, M. 2015. Personality strength and situational influences on behavior: A conceptual review and research agenda. Journal of Management, 41: 261-287.

Dawkins, S., Martin, A., Scott, J. \& Sanderson, K. 2013. Building on the positives: A psychometric review and critical analysis of the construct of Psychological Capital. Journal of Occupational and Organizational Psychology, 86, 348-370.

Dawkins, S., Martin, A., Scott, J., \& Sanderson, K. 2015. Advancing the conceptualization and measurement of psychological capital as a collective construct. Human Relations, 68: 925-949.

De Dreu, C. K. W., Nijstad, B. A., \& van Knippenberg, D. 2008. Motivated information processing in group judgment and decision making. Personality and Social Psychology Review, 12: 22-49.

DeRue, D. S. 2011. Adaptive leadership theory: Leading and following as a complex adaptive process. Research in Organizational Behavior, 31: 125-150.

Edwards, J., \& Parry, M. E. 1993. On the use of polynomial regression equations as an alternative to difference scores in organizational research. Academy of Management Journal, 36: 1577-1613.

Fairhurst, G. T., \& Uhl-Bien, M. 2012. Organizational discourse analysis (ODA): Examining leadership as a relational process. Leadership Quarterly, 23: 1043-1062.

Fleenor, J. W., McCauley, C. D., \& Brutus, S. 1996. Self-other rating agreement and leader effectiveness. Leadership Quarterly, 7: 487-506.

Fleenor, J. W., Smither, J. W., Atwater, L. E., Braddy, P. W., \& Sturm, R. E. 2010. Self-other rating agreement in leadership: A review. Leadership Quarterly, 21: 1005-1034.

González-Romá, V., Peiró, J. M., \& Tordera, N. 2002. An examination of the antecedents and moderator influences of climate strength. Journal of Applied Psychology, 87: 465-473.

Harms, P. D., \& Luthans, F. 2012. Measuring implicit psychological constructs in organizational behavior: An example using psychological capital. Journal of Organizational Behavior, 33: 589-594.

Harms, P. D., \& Spain, S. M. 2014. Follower perceptions deserve a closer look. Industrial and Organizational Psychology, 7: 187-191.

Harms, P. D., Vanhove, A., \& Luthans, F. 2017. Positive projections and health: An initial validation of the implicit psychological capital health measure. Applied Psychology, 66: 78-102.

Hayes, A. F. 2013. Introduction to mediation, moderation, and conditional process analysis. New York: Guilford Press.

He, W., Fehr, R., Yam, K. C., Long, L.-R., \& Hao, P. 2017. Interactional justice, leader-member exchange, and employee performance: Examining the moderating role of justice differentiation. Journal of Organizational Behavior, 38: 537-557. doi:10.1002/job.2133

Herdman, A. O., Yang, J., \& Arthur, J. B. 2017. How does leader-member exchange disparity affect teamwork behavior and effectiveness in work groups? The moderating role of leader-leader exchange. Journal of Management, 43: 1498-1523.

Hernandez, M., Eberly, M. B., Avolio, B. J., \& Johnson, M. D. 2011. The loci and mechanisms of leadership: Exploring a more comprehensive view of leadership theory. Leadership Quarterly, 22: 1165-1185.

Humphrey, R. H., Burch, G. F., \& Adams, L. L. 2016. The benefits of merging leadership research and emotions research. Frontiers in Psychology, 7: 1022.

Judge, T. A., \& Bono, J. E. 2000. Five-factor model of personality and transformational leadership. Journal of Applied Psychology, 85: 751-765.

Kark, R., \& Van Dijk, D. 2007. Motivation to lead, motivation to follow: The role of the self-regulatory focus in leadership processes. Academy of Management Review, 32: 500-528.

Koning, L. F., \& Van Kleef, G. A 2015. How leaders' emotional displays shape followers' organizational citizenship behavior. Leadership Quarterly, 26: 489-501. 
Kozlowski, S. W. J., Mak, S., \& Chao, G. T. 2016. Team-centric leadership: An integrative review. Annual Review of Organizational Psychology and Organizational Behavior, 3: 21-54.

Leary, M. R. 1989. Self-presentational processes in leadership emergence and effectiveness. In R. A. Giacalone \& P. Rosenfeld (Eds.), Impression management in the organization: 363-374. Hillsdale, NJ: Lawrence Erlbaum.

LeBreton, J. M., \& Senter, J. L. 2008. Answers to 20 questions about interrater reliability and interrater agreement. Organizational Research Methods, 11: 815-852.

Lee, A., \& Carpenter, N. C. 2017. Seeing eye to eye: A meta-analysis of self-other agreement of leadership. Leadership Quarterly. Advance online publication. doi:10.1016/j.leaqua.2017.06.00

Li, S., He, W., Yam, K. C., \& Li, S. 2015. When and why empowering leadership increases follower taking charge: A multilevel examination in China. Asia Pacific Journal of Management, 32: 645-670.

Luthans, F., Avolio, B. J, Avey, J. B., \& Norman, S. M. 2007. Positive psychological capital: Measurement and relationship with performance and satisfaction. Personnel Psychology, 60: 541-572.

Luthans, F., \& Youssef-Morgan, C. M. 2017. Psychological capital: An evidence-based positive approach. Annual Review of Organizational Psychology and Organizational Behavior, 4: 339-366. doi:10.1146/annurev-orgpsych-032516-113324

Luthans, F., Youssef-Morgan, C. M., \& Avolio, B. J. 2015. Psychological capital and beyond. Oxford, UK: Oxford University Press.

MacKinnon, D. P., Lockwood, C. M., \& Williams, J. 2004. Confidence limits for the indirect effect: Distribution of the product and resampling methods. Multivariate Behavioral Research, 39: 99-128.

Marks, S. R. 1977. Multiple roles and role strain: Some notes on human energy, time and commitment. American Sociological Review, 41: 921-936.

Meyer, R. D., Dalal, R. S., \& Hermida, R. 2010. A review and synthesis of situational strength in the organizational sciences. Journal of Organizational Behavior, 36: 121-140.

Morgeson, F. P., DeRue, D. S., \& Karam, E. P. 2010. Leadership in teams: A functional approach to understanding leadership structures and processes. Journal of Management, 36: 5-39.

Newman, A., Ucbasaran, D., Zhu, F., \& Hirst, G. 2014. Psychological capital: A review and synthesis. Journal of Organizational Behavior, 35: S120-S138.

Ng, K.-Y., Ang, S., \& Chan, K.-Y. 2008. Personality and leader effectiveness: A model of leadership self-efficacy, job demands, and job autonomy. Journal of Applied Psychology, 93: 733-743.

Ostroff, C., Atwater, L. E., \& Feinberg, B. J. 2004. Understanding self-other agreement: A look at rater and ratee characteristics, context and outcomes. Personnel Psychology, 57: 333-375.

Ostroff, C., Kinicki, A. G., \& Clark, M. A. 2002. Substantive and operational issues of response bias across levels of analysis: An example of climate-satisfaction relationships. Journal of Applied Psychology, 87: 355-368.

Owens, B. P., Baker, W., Sumpter, D. M., \& Cameron, K. 2016. Leader relational energy: Implications for job engagement and job performance. Journal of Applied Psychology, 100: 1203-1213.

Parker, S. K. 1998. Enhancing role breadth self-efficacy: The roles of job enrichment and other organizational interventions. Journal of Applied Psychology, 83: 835-852.

Pellegrini, E. K. 2015. Relational leadership through the lens of international LMX research. In T. N. Bauer \& B. Erdogan (Eds.), The Oxford handbook of leader-member exchange: 351-379. Oxford, UK: Oxford University Press.

Peterson, S. J., Balthazard, P. A., Waldman, D. A., \& Thatcher, R. W. 2008. Neuroscientific implications of psychological capital: Are the brains of optimistic, hopeful, confident, and resilient leaders different? Organizational Dynamics, 37: 342-353.

Quinn, R. W., \& Dutton, J. E. 2005. Coordination as energy-in-conversation. Academy of Management Review, 30: 36-57.

Quinn, R. W., Spreitzer, G. M., \& Lam, C. F. 2012. Building a sustainable model of human energy in organizations: Exploring the critical role of resources. Academy of Management Annals, 6: 337-396.

Rego, A., Marques, C., Leal, S., Sousa, F., \& Cunha, M. P. 2010. Psychological capital and performance of civil servants: Exploring neutralizers in the context of an appraisal system. International Journal of Human Resource Management, 21: 1531-1552.

Rego, A., Owens, B., Yam, K. C., Bluhm, D., Cunha, M. P., Silard, T., Gonçalves, L., Martins, M., Simpson, A. V., \& Liu, W. 2017. Leader humility and team performance: Exploring the mechanisms of team PsyCap and task allocation effectiveness. Journal of Management. Advance online publication. doi:10.1177/0149206316688941

Roberts, B. W., Harms, P. D., Smith, J. L., Wood, D., \& Webb, M. 2006. Using multiple methods in personality psychology. In M. Eid \& Ed. Diener (Eds.), Handbook of multimethod measurement in psychology: 321-335. Washington, DC: American Psychological Association. 
Scheier, M. F., Carver, C. S., \& Bridges, M. W. 1994. Distinguishing optimism from neuroticism (and trait anxiety, self-mastery, and self-esteem): A reevaluation of the Life Orientation Test. Journal of Personality and Social Psychology, 67: 1063-1078.

Schippers, M. C., \& Hogenes, R. 2011. Energy management of people in organizations: A review and research agenda. Journal of Business and Psychology, 26: 193-203.

Schneider, B., Salvaggio, A. N., \& Subirats, M. 2002. Climate strength: A new direction for climate research. Journal of Applied Psychology, 87: 220-229.

Schriesheim, C. A. 1997. Substitutes-for-leadership theory: Development and basic concepts. The Leadership Quarterly, 8: 103-118.

Seibert, S. E., Sargent, L. D., Kraimer, M. L., \& Kiazad, K. 2016. Linking developmental experiences to leader effectiveness and promotability: The mediating role of leadership self-efficacy and mentor network. Personnel Psychology. Advance online publication. doi:10.1111/peps.12145

Shanock, L. R., Baran, B. E., Gentry, W. A., Pattison, S. C., \& Heggestad, E. D. 2010. Polynomial regression with response surface analysis: A powerful approach for examining moderation and overcoming limitations of difference scores. Journal of Business and Psychology, 25: 543-554.

Shirom, A. 2010. Feeling energetic at work: On vigor's antecedents. In A. B. Bakker \& M. P. Leiter (Eds.), Work engagement: A handbook of essential theory and research: 69-84. New York: Psychology Press.

Snyder, C. R., Sympson, S. C., Ybasco, F. C., Border, T. F., Babyak, M. A., \& Higgins, R. L. 1996. Development and validation of the State Hope Scale. Journal of Personality and Social Psychology, 70: 321-35.

Spreitzer, G., Sutcliffe, K., Dutton, J., Sonenshein, S., \& Grant, A. M. 2005. A socially-embedded model of thriving at work. Organization Science, 16: 537-549.

Story, J., Youssef, C. M., Luthans, F., Barbuto, J. E., \& Bovaird, J. 2013. Contagion effect of global leaders' positive psychological capital on followers: Does distance and quality of relationship matter? International Journal of Human Resource Management, 24: 2534-2553.

Sy, T., \& Choi, J. N. 2013. Contagious leaders and followers: Exploring multi-stage mood contagion in a leader activation and member propagation (LAMP) model. Organizational Behavior and Human Decision Processes, 122: 127-140.

Uhl-Bien, M. 2006. Relational leadership theory: Exploring the social processes of leadership and organizing. Leadership Quarterly, 17: 654-676.

van Dierendonck, D., Stamn, D., Boersma, P., de Windt, N., \& Alkema, J. 2014. Same difference? Exploring the differential mechanisms linking servant leadership and transformational leadership to follower outcomes. Leadership Quarterly, 25: 544-562.

Van Kleef, G. A. 2009. How emotions regulate social life: The emotions as social information (ESASI) model. Current Directions in Psychological Science, 18: 184-188.

Van Kleef, G. A. 2010. The emerging view of emotion as social information. Social and Personality Psychology Compass, 4/5: 331-343.

Van Kleef, G. A., De Dreu, C. K. W., \& Manstead, A. S. R. 2010. An interpersonal approach to emotion in social decision making: The emotions as social information model. Advances in Experimental Social Psychology, 42: 45-96.

Van Kleef, G. A., Homan, A. C., Beersma, B., van Knippenberg, D., van Knippenberg, B., \& Damen, F. 2009. Searing sentiment or cold calculation? The effects of leader emotional displays on team performance depend on follower epistemic motivation. Academy of Management Journal, 52: 562-580.

Van Kleef, G. A., van den Berg, H., \& Heerdink, M. W. 2015. The persuasive power of emotions: Effects of emotional expressions on attitude formation and change. Journal of Applied Psychology, 100: 1124-1142.

Van Knippenberg, D., \& Van Kleef, G. A. 2016. Leadership and affect: Moving the hearts and minds of followers. Academy of Management Annals, 10: 799-840.

Visser, V. A., van Knippenberg, D., van Kleef, G. A., \& Wisse, B. 2013. How leader displays of happiness and sadness influence follower performance: Emotional contagion and creative versus analytical performance. Leadership Quarterly, 24: 172-188.

Vogel, B., \& Bruch, H. 2012. Organizational energy. In K. Cameron \& G. M. Spreitzer (Eds.), Oxford Handbook of Positive Organizational Scholarship: 691-702. New York: Oxford University Press.

Wagnild, G. M., \& Young, H. M. 1993. Development and psychometric evaluation of the resilience scale. Journal of Nursing Measurement, 1: 165-178.

Walter, F., \& Bruch, H. 2010. Structural impacts on the occurrence and effectiveness of transformational leadership: an empirical study at the organizational level of analysis. Leadership Quarterly, 21: 765-782. 
Watzlawick, P., Beavin, J. H., \& Jackson, D. D. 1967. Pragmatics of human communication: A study of interactional patterns, pathologies, and paradoxes. New York: Norton.

Wood, D., Harms, P., \& Vazire, S. 2010. Perceiver effects as projective tests: What your perception of others say about you. Journal of Personality and Social Psychology, 99: 174-190.

Wu, J. B., Tsui, A. S., \& Kinicki, A. J. 2010. Consequences of differentiated leadership in groups. Academy of Management Journal, 53: 90-106.

Yam, K. C., Christian, M., Wei, W., Liao, Z., \& Nai, J. in press. The mixed blessing of leader sense of humor: Examining costs and benefits. Academy of Management Journal.

Youssef, C. M., \& Luthans, F. 2012. Positive global leadership. Journal of World Business, 47: 539-547.

Youssef-Morgan, C. M., \& Luthans, F. 2015. Psychological capital and well-being. Stress and Health, 31: 180-188.

Yukl, G. 1999. An evaluation of conceptual weaknesses in transformational and charismatic leadership theories. Leadership Quarterly, 10: 285-305.

Zhang, X.-A., Li, N., Ullrich, J., \& van Dick, R. 2015. Getting everyone on board: The effect of differentiated transformational leadership by CEOs on top management team effectiveness and leader-rated firm performance. Journal of Management, 41: 1898-1933.

Zohar, D. \& Luria, G. 2004. Climate as a social-cognitive construction of supervisory safety practices: Scripts as proxy of behavior patterns. Journal of Applied Psychology, 89: 322-333. 